\title{
Public Ethos in the Pandemic Rhetorical Situation: Strategies for Building Trust in Authorities' Risk Communication
}

\author{
Truls Strand Offerdal ${ }^{1} \oplus$, Sine Nørholm Just ${ }^{2} \oplus$, and $\emptyset$ yvind Ihlen ${ }^{1} \oplus$ \\ 1. Department of Media and Communication, University of Oslo, Oslo, Norway \\ 2. Roskilde University, Denmark
}

\begin{abstract}
As illustrated by the COVID-19 pandemic, risk and crisis communication are crucial responsibilities of modern governments. Existing research on risk and crisis communication points to the importance of trust, both as a resource in and an end goal of communicative activities. In this paper, we argue that revisiting the classical rhetorical concept of ethos in combination with the modern concept of the rhetorical situation can contribute to fitting responses in risk and crisis communication. The paper examines how appeals to ethos may build trust in health authorities' public communication during the COVID-19 pandemic. Through interviews and participant observation in public health institutions that handle the COVID-19 pandemic in Norway, the paper finds that understanding the rhetorical situation of the pandemic allows for a better understanding of the available means of persuasion. For instance, through the active communication of transparency and independence when faced by uncertainty and rapidly changing information.
\end{abstract}

KEYWORDS: risk communication, crisis communication, pandemic, rhetorical situation, ethos, trust, trustworthiness

The COVID-19 pandemic has shone a light on one of the central aspects of government communication work, namely the ability to ensure that citizens find the public messages, recommendations, and directives given in a time of crisis credible and trustworthy. Various studies on risk and crisis communication

CONTACT Truls Strand Offerdal (D) - E-mail: t.s.offerdal@media.uio.no - Department of Media and Communication • University of Oslo • Gaustadalléen 21 • 0349 Oslo, Norway 
have emphasized the role of trust in ensuring that messages are heard (e.g., Boyd et al. 2019; Liu et al., 2016), some going so far as calling trust "a primary driver of whether communities positively respond to government communication" (Liu \& Mehta, 2020, p. 1). Attempts to establish best practices for risk and crisis communication have also pointed to trust as a central concept (Covello, 2010; Seeger, 2006), especially when a risk situation develops into a crisis (De Vocht et al., 2016).

Despite the consensus on the importance of trust, the concept is often not clearly defined nor conceptualized (Chryssochoidis et al., 2009; Liu \& Mehta, 2020). In terms of the practice of establishing, reconstructing, or maintaining trust, literature on risk and crisis communication often points to such aspects as demonstrating honesty, empathy, and competency (Meredith et al., 2007) or openness and shared interest (Eiser et al., 2009). This list of strategies bears a clear resemblance to, and is in part inspired by, the classical rhetorical concept of ethos, defined as the speaker's demonstration of competency, virtue, and goodwill (Aristotle, trans. 2006; Peters et al., 1997). Generally, trust can be seen as a relational concept, often informed by rational assessment and experiences; a popular definition by Hardin sees trust as "A trusting B to do X" (2001). Trustworthiness can be understood as more of a moral quality, something you are perceived as, in order to support trust being placed in you (Hardin, 1996). We argue that studying trustworthiness through the rhetorical construct of ethos provides a clear foundation for the conceptualization of trust, generally, and holds advantages for the application of the concept within crisis and risk communication, specifically.

First, ethos is a constantly renegotiated quality; it is an evaluation of the communicator that is performed by the audience and based on rhetorical artifacts, communicated at particular times as responses to particular problems (McCroskey, 1966). Second, rhetorical theory allows for a more nuanced understanding of efficient risk and crisis communication; in crisis situations, communication is rarely conducted by one single actor with supreme authority. Instead, the official response to the pandemic is the responsibility of overlapping official actors, from public health institutions (PHIs), such as the U.S. Centers for Disease Control 
and Prevention (CDC), to state and local political entities, governments, and decision makers. Here, the modern theory of the rhetorical situation (Bitzer, 1968) may provide a structured process for identifying the constraints and opportunities available to organizations.

In order to investigate how PHIs may draw on ethos-based communication during the rhetorical situation of a pandemic, we have chosen to focus on two such organizations, operating in the national context of Norway. Thus, our research questions are:

RQ1: How did the Norwegian PHIs attempt to strengthen, maintain, or rebuild ethos through their communication during the first 10 months of the COVID-19 pandemic?

RQ2: How were the strategies for strengthening ethos influenced by the rhetorical situation of the pandemic?

RQ3: What are the general implications of the Norwegian PHIs' use of ethos-based communication in the rhetorical situation of the COVID19 pandemic for risk and crisis communication?

In order to answer these questions, we have conducted a qualitative study based on interviews and participant observation during Spring and Autumn 2020 in the communication departments of two Norwegian PHIs.

Norway is generally recognized as a country characterized by high trust in institutions and largely built its pandemic response on voluntary adherence to guidelines. So far, the country has avoided some of the more dramatic effects of the pandemic in terms of the numbers affected, without having to resort to more invasive measures, such as curfews (Ursin et al., 2020). Internal weekly reports on trust made available to us consistently indicated that 80 to $90 \%$ of the population describe having high trust in the health authorities' handling of the crisis ( 4 or 5 on a 5-point scale). We argue that studying the rhetorical construction of trustworthiness in a country where it seems to have been effective, both in the past and during the pandemic, should be of interest to researchers and practitioners of risk and crisis communication.

The paper is structured as follows: We will establish the context of our study by presenting the structure of the Norwegian health 
authorities before reviewing the relevant literature and presenting our theoretical framework. Subsequently, we outline the methodological framework and move on to the analysis of our case organizations' communication work during the first 10 months of the pandemic.

\section{The Norwegian Health Authorities' Role in Communicating the Pandemic Response}

Most countries have one or several PHIs, although their role, autonomy, and function differ. Norway has two main PHIs with central roles during pandemics, the Norwegian Institute of Public Health (NIPH) and the Directorate of Health (DOH). While the NIPH is responsible for tracking and reacting to outbreaks of infectious or food-borne diseases, both organizations hold a central role in the plans for pandemic response (Norwegian Department of Health, 2014). The NIPH has a stronger emphasis on research than the DOH (NIPH, 2016), whereas the latter "shall improve the health of the citizens and the community as a whole . . by virtue of its role as an executive agency, as a regulatory authority and as an implementing authority in areas of health policy" (Norwegian Directorate of Health, 2019, Public mandate section). In combination, and collaborating closely with the Norwegian government to whom both ultimately report, the two PHIs hold the necessary expertise and authority to establish and effectuate the national pandemic response.

\section{Literature Review}

In discussion of crisis communication, pandemics are typical examples of crises, whereas communicating about health risks, such as potential infectious diseases, is often mentioned as a form of risk communication. In situating the COVID-19 pandemicand, hence, our data material-it is relevant to consider the interrelations of risk and crisis. Generally, we agree with Seeger (2006) who asserts that while the two terms describe slightly different functions, they are often unified in practice. During the COVID19 pandemic, some functions of PHI communication could best be 
described as risk communication. Simultaneously, the PHIs were clearly involved in crisis communication, attempting to manage and provide information about the ongoing crisis and potential developments while maintaining their own credibility and position as organizations. It might be possible to break down individual rhetorical acts or statements in order to define them as either crisis or risk communication, but issues of trust clearly cut across the two domains. Hence, we sidestep the question of the interrelations between risk and crisis communication during the pandemic at present and, instead, aim to identify and detail the role of ethos across the PHIs' communication strategies.

In order to examine the role of ethos-based communication during the pandemic, we will first introduce the concept of the rhetorical situation. We argue that this contextual analytical framework is highly suitable to capture the challenges and possibilities for communication from public institutions during a pandemic.

\section{Public Communication Work, Pandemics, and the Rhetorical Situation}

The concept of the rhetorical situation was first introduced by Bitzer (1968), who considered it to consist of three elements, an exigence or pressing problem that can be influenced through communication, an audience that the rhetor aims at persuading, and constraints in the form of rhetorical, physical, or cultural conditions of possibility for achieving the desired outcome (Bitzer, 1968). Subsequently, the concept has been nuanced theoretically and adapted to current media environments, as scholars have argued that (technological) affordances and other (media) possibilities should be included in analyses of the rhetorical situation in order to avoid a deterministic understanding of rhetoric (Ihlen, 2011; Kjeldsen, 2015).

The framework of the rhetorical situation is important for our understanding of the communication of the PHIs during the pandemic. Establishing this starting point allows us to incorporate some of the contextual challenges and opportunities faced by organizations during a pandemic, as already presented in crisis and risk communication literature. 
One existing study specifically examines how the Hong Kong government dealt with challenges of trust during the 2003 SARS outbreak (Lee, 2009). Here, factors that differentiate public crisis management from similar work in private companies are identified. One such challenge can arise from the complexity of public bureaucracy which might result in inconsistencies in statements made by different parts of the government. This can enhance communication and coordination problems between the government and the public and create an impression of sub-optimal crisis management that shapes present and future expectations of the government as well as the public's willingness to adhere to advice (Lee, 2009).

Similarly, Liu and Horsley (2007) argue that public sector communication work is shaped by several environmental and contextual challenges, including the political aspects of all decisions, the specific expectation of serving the public and increased scrutiny from the media and the public. At the same time, inconsistencies and disagreements between agencies and actors can also be a result of differences in interpretations of what technical or scientific information might be appropriate to divulge to the public (Chess \& Clarke, 2007).

Existing research has also pointed to contextual factors in trust between various types of organizations. While private industry received the greatest increase in trust scores through demonstrating openness, the effects on trust in government institutions was most significant when they demonstrated competency. This can be taken to indicate that organizational trust is increased by breaking stereotypes such as public institutions being impersonal or bureaucratic or private companies valuing their own profit over the public good (Peters et al., 1997).

Although these studies do not use the terminology of the rhetorical situation, they identify contextual and situated factors in what rhetorical strategies constitute a fitting response in each instance. We argue that the rhetorical situation as a theoretical lens can contribute to a better understanding of these factors. In order to add to these insights, we turn to the question of how ethos may help address the constraints of the current situation of the PHIs. 


\section{The Rhetorical Tradition-Organizational Rhetoric and Ethos}

Since its inception, the aim of rhetoric has been to systematically study the various means available for persuasion through communication (Aristotle, trans. 2006, 1.2.1). While the ancient tradition had a focus on individuals as rhetors, the modern field of organizational rhetoric is dedicated to the study of communication on behalf of larger entities such as private companies and public authorities (Ihlen \& Heath, 2018). This field rests on the premise that organizations must communicate as collective actors in order to achieve their goals. Hence, scholars of organizational rhetoric study how organizations go about their communicative business, drawing on a wide array of work from both classical and modern rhetoric (Ihlen \& Heath, 2018).

Here, ethos, the appeal to the communicator's trustworthiness, is a central mode of persuasion (Baumlin \& Scisco, 2018), as this is particularly challenging for a collective actor who must establish itself through communication. Ethos is generally understood as consisting of three dimensions: competency, virtue, and goodwill. Speakers who demonstrate these capacities, it is implied, will be more readily believed than others (Aristotle, trans. 2006, 2.2.5).

In this article, we explore how organizations may use rhetorical appeals to ethos to influence audiences' trust in them and their messages. For the practical analysis, we will operationalize the three core parts of ethos as outlined by Aristotle combined with modern notions of organizational ethos. In exploring the dimension of practical wisdom as this relates to the demonstration of competency, such practical wisdom can be demonstrated or strengthened through the use of formal or scientific language (Ihlen, 2009); it can also be formalized as expertise, operationalized in messages that present scientific methods or approach $(\mathrm{Xu}$ et al., 2020). The dimension of virtue has previously been operationalized in rhetorical theory as the use of partnerships with trustworthy organizations and endorsements (Ihlen, 2009), while persuasion theory has operationalized the related concept of honesty as being open about potential negative sides of the organization's own position ( $\mathrm{Xu}$ et al., 2020). 
Finally, goodwill has been tied to the demonstration of understanding, empathy, and responsiveness to communication from others (McCroskey \& Teven, 1999). In analyzing interview transcripts and field notes, we have treated segments that concern any of these elements as connected to the rhetorical construction of the organization's ethos and analyzed them accordingly.

\section{Method}

The data material for the paper consists of (1) field notes gathered through participant observations in the communication departments of the NIPH and DOH during the Spring and Fall of 2020 (specifically, 6 days NIPH and 4 days DOH during March and April followed by 5 additional days of observation at NIPH in August); and (2) eight in-depth, qualitative semi-structured interviews, four in each organization, during the Fall of 2020.

Participant observation was chosen both as a way of capturing the complexities of organizations as communicators (Ybema et al., 2009, pp. 1-3) and as a way of ensuring a real-time perspective on how the communication work was conducted and negotiated during the height of the pandemic. As "a method for producing data about realities, a way to systematically transcribe processes as they are pursued and narrated by research subjects and observed and experienced by the researcher" (Nielsen, 2012, p. 190), participant observation can be helpful in describing complex social realities. It can be difficult to capture the uncertain and changing nature of crises and disasters in structured and systematic fieldwork (Horsley, 2012), but our study was facilitated by the fact that we had already established contact with one PHI and done extensive background research on the plans for pandemic communication prior to the start of the COVID-19 pandemic. As part of negotiating access, a confidentiality agreement concerning classified and personal information was signed. During observations, field notes were gathered by hand for each individual day, along with reflective notes about possible interpretations, challenges, concerns, and areas for further investigation.

In order to analyze and interpret the results of ethnographic studies, it is necessary to triangulate the data gathered through 
observation. This was done methodologically by supplementing with qualitative interviews and through a triangulation of sites for observation with time spent at two different sites, with two different organizations at two different times (Schwartz-Shea \& Yanow, 2009).

The interviews included in the study were semi-structured, lasting around one hour each. Prior to the interviews, an interview guide was created, addressing central questions concerning communication during the pandemic as well as more general strategies for crisis and risk communication in the organizations. The semi-structured approach allowed for the interviewer to adapt the questions asked, based both on replies given to previous questions and the roles and responsibilities of the individual interview subject within the communication departments. This approach to interviews was informed by Kvale and Brinkmann's (2009) sevenstep approach to qualitative interviews. In selecting interview subjects, we focused on covering different aspects of the organizations' communication work, picking both general managers and employees working in the various internal teams responsible for press work, social media and owned media. With the exception of one online conversation, all interviews were conducted in person.

Field notes and transcripts of the interviews were analyzed in order to thematically identify segments concerning issues of trust and trustworthiness. Subsequently, selected illustrative quotes from the interviews were translated by the first author for inclusion in the paper. The final included quotes were presented to the interview subjects and approved. While we aim to provide rich descriptions and interpretations grounded in the perceived reality of employees in the chosen organizations, we do not claim generalizability from our cases to all PHIs facing a pandemic. Informed by the concept of the rhetorical situation with its emphasis on contextual affordances and hindrances to efficient rhetorical action, we argue that such generalization would, at best, be thin and, at worst, misleading. We do, however, intend for our analysis to be helpful both to academics and to practitioners, as we seek to draw lessons from what is surely not the best-case scenario but maybe one "as-good-as-it-gets" case for communicating the COVID-19 pandemic response. 


\section{Results and Discussion}

\section{The Pandemic as a Rhetorical Situation}

As mentioned initially, we argue that the rhetorical situation (Bitzer, 1968) is an important theoretical lens for understanding the complexities, challenges, and affordances surrounding public sector communication work during the pandemic. In order to understand how the situation shaped the choices made by the PHIs included in the study, it is first necessary to understand what rhetorical problem they attempted to solve through their communication. The main objective is simple enough; PHIs attempted to convey scientifically sound information about the nature of the pandemic, the official state response as well as recommendations for additional actions for individuals to protect themselves and contribute to halting the spread of the pandemic. As one interview subject, $\mathrm{H}_{1}$ at the $\mathrm{DOH}$ described it:

\footnotetext{
The goal of our communication has been to gain adherence from the population, to have trust. We have worked along three axes: Building knowledge, achieving trust, and ensuring that people have the right behavior. That last one is hard, because it is about changing behavior. (H1, DOH, Personal communication, 10.2020)
}

The broadly defined exigence of the pandemic means that the rhetorical audience for organizations such as NIPH and the DOH becomes the entire population of their country, primarily the general public, as these are "the mediators of change" who can resolve the situation by acting in compliance with the PHIs' advice. Simultaneously, the PHIs also communicate with several other target groups, such as the medical community and the government itself.

Communicating to such a wide target group can be challenging, and subgroups within the general public have been identified as particularly important, either because they are not reached by general communication through the media or because statistics and surveys have shown that they are not adhering to the guidelines as diligently as the rest of the population. The latter was, for instance, evident during observations of the production and promotion of an instruction video for the correct use of face masks 
where both the choice of actor and targeting of the video aimed at reaching people between the age of 20-30, particularly males.

In our analysis of the rhetorical situation, we must understand the contextual constraints as well as the tools and resources that are available to the PHIs to resolve the exigence. As a starting point, the Norwegian PHIs are well-known and have a certain amount of pre-built trustworthiness and recognition among the public. For instance, polling conducted prior to the pandemic showed that $60 \%$ of the population had a positive impression of the $\mathrm{DOH}$ (IPSOS, 2020). Further, both organizations have pre-existing plans for risk and crisis communication as well as valuable experiences from previous public health crises in the country (Brekke et al., 2017). Being official parts of the national crisis response also offers tools that are not necessarily available to communication departments in private industry or the corporate world, such as the ability of communicating directly to all cellular devices in the country, or direct lines of communication with health professionals all over the country.

Regarding the ethos of the PHIs as a situational affordance as well as a rhetorical strategy, we argue that their role and function in the overall system of health care and governance strengthens their initial credibility; they are not organizations who have to build their reputation from scratch but are already established as the scientific authority when it comes to public health. In an interview conducted prior to the outbreak of the COVID-19 pandemic, $\mathrm{R} 1$ at the NIPH described how establishing trust is central to communication work for the organization:

Building trust in the public is a frequent topic for us. We are aware that the population presently shows a high degree of trust in us, and we work to obtain and maintain this trust. We are especially aware that we need this trust in a crisis situation, in order for our advice to be listened to and followed. (R1, NIPH, Personal communication, 01.2020)

The pre-established trust should be seen as an important affordance that influences how the organizations handle the rhetorical problems of the pandemic. 
In the following sections we will identify and discuss some of the rhetorical strategies for strengthening ethos employed by the PHIs in Norway, relating these strategies to the complexity of the rhetorical situation.

\section{Ethos through Competency/Practical Wisdom}

First, we consider the strategy of building ethos through the display of practical knowledge, understood as trustworthiness derived from the impression that the speaker is competent, qualified, and knows what they are talking about (Baumlin \& Scisco, 2018; Ihlen, 2009). One of the challenges of risk and crisis situations in general, and pandemics in particular, is that they are characterized by uncertainty, both among the public and among the experts (Seeger \& Sellnow, 2019). One interesting example is from the informant $\mathrm{H}_{1}$ at $\mathrm{DOH}$ who emphasized the need to increase knowledge among the population as part of the communication work during the pandemic:

We attempt to build an understanding of the situation we are all in [...] increasing the level of knowledge and the competency among every individual. I think that is quite central because if you know, understand and see the context, it becomes a lot easier to trust in the decisions and the general handling that is being done. So, we have spent a lot of time explaining, simplifying and so on, and it's been quite complex because our advice has been changing quite frequently and the advice has been quite complicated through the pandemic. (H1, DOH, Personal communication, 10.2020)

Here, the organization seeks to build its own competency in and through active attempts to build the knowledge and understanding of the audience. The situation makes it necessary to take the time to repeat and explain in detail the various aspects of their decisions in order to make it possible for the audience to understand and accept the measures as necessary. Simultaneously, the organization strengthens its competency and expertise insofar as the audience deems it to be knowledgeable and adept at communicating its knowledge.

Along similar lines, several informants spoke of strategies to adapt to and improve communication through the use of feedback 
from the public, particularly when the feedback indicated that the communication might be confusing or unclear. One informant, $\mathrm{H}_{4}$ at the $\mathrm{DOH}$, described the feedback process as follows:

Continuous adaptation and adjustment, I think so [that it was important for their successful communication work], we call it the golden triangle in our team. We publish on [health website], people ask questions through the phone or through our chat-bot as well as feedback through [health website] and then we revise it. (H4, DOH, Personal communication, 10.2020)

While giving clear and easily understood advice might seem like an obvious tactic of risk and crisis communication, the uncertainty of the COVID-19 pandemic presents a potential challenge that our informants had to react to. Noting how the need to communicate quickly is in conflict with the desire to communicate correctly, another informant, $\mathrm{H}_{2}$ at the $\mathrm{DOH}$, said:

If we had been standing there, unsure about what to say, being late with our comments or said "no, we have to get back to you on that," "we don't know," or "I can't say," if we had chosen that way of communicating I think we would have started out with a deficit [in trust] [.] And that's why. [the assistant director of the $\mathrm{DOH}$ ] as well as [the director of the $\mathrm{DOH}$ ] has been very clear and very skilled at communicating through the entire period, but they have, even when we do not know, said that "I can't say for sure, but." So, we have taken that approach with a lot of things, and I think that has worked well. (H2, DOH, Personal communication, 10.2020)

What the informant describes here, can in many ways be seen as a balancing act between different best practice principles of crisis communication (Covello, 2010; Seeger, 2006; Seeger \& Sellnow, 2019), defending the trustworthiness of the organization while simultaneously recognizing the inherent uncertainty of the situation and answering a need for information even when information is scarce or contested.

The fact that several different organizations, who did not always agree with each other, were involved in official communication about the pandemic can be seen as a characteristic of the rhetorical situation that challenges the organizations' ability to demonstrate practical wisdom. This was not only the case in the COVID-19 
pandemic, but also during the Norwegian handling of the $\mathrm{N}_{1} \mathrm{H}_{1}$ pandemic (Brekke et al., 2017). When two different organizations, both billed as experts responsible for devising strategy, disagree with each other, it could potentially hurt the ethos, not only of the individual organizations but of the official pandemic response as a whole. This concern seemed strong during the first round of observations at the NIPH in March, as the issue of how to handle conflicting statements between the organizations and the $\mathrm{DOH}$, who at the time held separate press conferences each day, was intensely discussed at meetings and in casual encounters between the lead author and members of the communication staff. In the follow-up interviews we asked informants about these episodes of conflicting opinions and their potential effect on ethos, receiving varied answers. One informant from the $\mathrm{DOH}$, for instance, emphasized that the collaboration between the PHIs had worked out well. When asked about potential negative impact on trust, the informant, $\mathrm{H}_{2}$, replied that:

You would think so, but I do not think it has led to our position being weakened in daily communication. Maybe it could have been in certain periods [of the pandemic] if there had been a lot of cases centered around $[\mathrm{NIPH}]$ saying this thing and $[\mathrm{DOH}]$ saying that thing. There have been some cases like that, where it has been a bit contested, but I don't think there have been too many. There haven't been that many big media cases about conflict. (H2, DOH Personal communication, 10.2020)

Most respondents seem to agree that conflicting advice between the different institutions has not been that big of a problem for trustworthiness in communication about the pandemic, at least not in its early stages. In fact, several informants highlighted that communication and collaboration between the different organizations seemed to have worked well throughout the crisis, with daily meetings and coordination efforts.

That is not to say that the number of organizations involved did not lead to challenges in the rhetorical work during the pandemic. During observation at the two PHIs, it was repeatedly clear that an important constraint was the fact that neither organization was the ultimate authority regarding what advice would eventually 
be given and what regulations would be introduced. Instead, this was the prerogative of the government/the minister of health. This was especially evident during the period of observations at the $\mathrm{DOH}$ in April 2020. The lead author followed the communication department in the days prior to an important press conference, which was to announce the first instances of easing of regulations, including the opening of kindergartens and the lifting of a controversial ban on visits to secondary property such as cabins. The week before this press conference, recommendations had been given by the DOH and the NIPH in a report. However, early feedback indicated that recommendations in this report were likely to be overruled by the government. This led the PHIs to spend significant time and energy strategizing and preparing for a rhetorical challenge where their expert opinion was likely to be overruled. This all changed a few hours before the press conference when the PHIs were notified through email that the final decision would end up being largely in line with the recommendations from the $\mathrm{DOH}$, with the exceptions of a few dates being pushed back.

Bringing this back to our theoretical framework, we would argue that we can see clear examples of the rhetorical situation challenging the use of ethos strategies tied to practical knowledge. However, as the next section will show, the organizations were able to draw on other dimensions of ethos in ways that mollified the negative consequences of challenges to the dimension of practical knowledge.

\section{Ethos through Demonstrations of Virtue}

Ethos through the demonstration of virtue was visible in the answers from several of our informants in various ways, particularly through the perceived independence of the NIPH. One example highlights how disagreement between authorities, which might challenge ethos through competency (Baumlin \& Scisco, 2018), can actually strengthen the overall trustworthiness, as it displays openness and honesty:

One of the things that has contributed to people trusting us has been that we have been open about what we recommend, even when the government has decided on something else. [ . . . ] At least that is 
something I believe should strengthen the trust in the recommendations. (R2, NIPH, Personal communication, 10.2020)

Other informants similarly pointed to the importance of professional honesty to establish trustworthiness:

Being open, to be transparent so that it does not seem like you are holding anything back in your professional assessment. Show that we are not gagged, we are definitely part of the team, but we make our own decisions and are free to express them. I think that gives credibility. (R7, NIPH, Personal communication, 10.2020)

Through a rhetorical lens, we can understand what is described here as a fitting response to a rhetorical situation where the presence of several organizations might challenge the ability to build trust through the demonstration of practical wisdom. Instead of being weakened by the presence of conflicting opinions, the organizations are able to present their willingness to stand by their opinions, even if they are challenged or ignored by other experts, as a demonstration of virtue, in this case professional integrity, honesty, and the courage of conviction.

During observations at the NIPH in the Fall of 2020, it was also possible to observe the active preservation of virtue in the form of guarding the perceived independence of the organization from the political leadership of the Ministry of Health and Care Services $(\mathrm{MOH})$. When the governing party and the opposition were having a public dispute concerning the recommendation to restrict the operation of bars and nightclubs, the $\mathrm{MOH}$ inquired if the NIPH would be able to provide scientific backing for the policy. The NIPH feared that this could be seen as them being a party in a political disagreement and decided it would not provide such backing. In the end, the $\mathrm{MOH}$ used numbers provided by the NIPH as part of their weekly reports about sites and locations for transmission of the virus, but without the NIPH being perceived as an active part responding to the desires of the government.

\section{Ethos through Goodwill}

One central constraint in the rhetorical situation faced by the organizations in this study is that they are public and partially 
bureaucratic organizations. Expectations tied to such organizations' language, tone, and emotional distance could be seen as barriers to their demonstration of goodwill (Liu \& Horsley, 2007; McCroskey \& Teven, 1999). Personal, emotional, and informal communication, classical strategies for emphasizing goodwill, are not traits traditionally associated with public sector organizations-and while demonstrating such traits might strengthen the display of goodwill, it could lower trustworthiness in other respects.

In this light, it is interesting that both organizations showed signs of active use of rhetorical strategies that display empathy and even identification with the audience, and several respondents mentioned that they believed these strategies had helped them in securing their audiences' trust. For instance, $\mathrm{R}_{3}$ at the NIPH provided the following evaluation of the active use of social media:

And we got feedback last week where it was clear throughout that they had trust in us, but also our way of speaking to them [the audience], the ones commenting appeared to enjoy the way we talked to them. That it is not the typical government or public service way of speaking. Many would think that formality would increase trust, but I think you benefit from having a more personal tone. (R3, NIPH, Personal communication, 09.2020)

Understood as a rhetorical strategy for strengthening ethos, the use of personal, informal language as well as engaging in dialogue through social media demonstrates to the audience that the speaker, in this case the NIPH, considers audience members as individuals and cares enough about them to address them individually (McCroskey \& Teven, 1999).

Interestingly, this approach to dialogue through social media does not seem to have been prioritized at the $\mathrm{DOH}$ where the communication department made an early decision to emphasize what they described as "one-to-many" communication. However, some strategies for demonstrating goodwill were visible in how this "one-to-many" communication was designed. One informant, for instance, mentioned how they took care in ensuring a sense of safety in the reader and taking steps to include more personal language such as the use of "you" and "those close to you" in their 
messages. This description, of something as simple as the use of the word "you" being effective in building trustworthiness for the organization, could be related to the idea of breaking with the stereotype of the cold and impersonal public organization (Peters et al., 1997). At the same time, this informant emphasizes the more general point that receiving the information needed to feel safe can strengthen the impression that the organization has the citizens' best interests in mind.

While the PHIs were willing to actively build goodwill aspects of ethos in their communication, they were also aware of the expectations placed on their communication as public institutions. This was, perhaps, best exemplified in observations at the $\mathrm{DOH}$ during a meeting discussing a concrete campaign for a contact-tracing app. During the meeting, participants discussed a planned promotional video using well-known comedians and humor to promote the message that if enough people used the app it would be easier to reopen society. It became clear from the discussion that the general tone and humor seemed to break with the participants' idea of tone and content from the organizations, and the campaign, ultimately, did not make it past the planning stage. This observation, then, points to the issue of balancing the various appeals to ethos and not prioritizing one aspect at the expense of others.

\section{Conclusion}

Returning to our initial research questions, we can conclude that rhetorical strategies relying on the demonstration of ethos (Aristotle, trans. 2006; Baumlin \& Scisco, 2018) were clearly visible in the communication strategy of the Norwegian PHIs included in the study. Various aspects of demonstrating practical knowledge, virtue, and goodwill (Baumlin \& Scisco, 2018; McCroskey \& Teven, 1999) were brought up by informants and appeared as central concerns during participant observation. However, the demonstration of ethos dimensions did not take the form of simply checking boxes or following existing principles, but had to be adapted and changed according to a changing and challenging rhetorical situation (Bitzer, 1968). 
Relying on our qualitative approach, particularly participant observations, allowed us to capture how this rhetorical situation was shaped by aspects pertaining to the character of the pandemic as well as by conditions related to the PHIs' position within the Norwegian system of pandemic response as public institutions (Peters et al., 1997). Simultaneously, the affordance of preexisting public trust in Norwegian institutions meant that the organizations' main task was to maintain their trustworthiness, rather than having to build it from scratch. In practice, this might have influenced how the PHIs were able to pivot away from dimensions of trust that were challenged by the rhetorical situation by, for instance, relying on virtue dimensions when practical knowledge was rendered unavailable. Honesty and the courage to stick by your views in the face of disagreement was highlighted by informants as strengthening their ethos.

At the same time, there are important limitations to our study. First, contextualization is an inherent condition of our approach. While we can describe the pandemic response of the Norwegian PHIs as fitting to their specific situation, using the same strategies in another context might have led to a different result. In a country such as Sweden, where PHIs have more authority and autonomy in designing and executing the pandemic response (Jakobsen, 2020), navigation of the inherent uncertainty of a global pandemic has taken a different form. Further, even within the same country, we would probably have reached different conclusions had this study been focused on government communication work, originating from the $\mathrm{MOH}$ or from the office of the prime minister. Finally, there is reason to believe that results would have been different in studies conducted in countries with lower levels of pre-existing societal trust.

These limitations point to the importance of a situated, rhetorically grounded approach to further research on risk and crisis communication, one that incorporates an understanding of the rhetorical situation. Further research that details the rhetorical situations of responding to the COVID-19 pandemic in various contexts can contribute to the field of risk and crisis communication by charting some of the more common challenges to building trust 
in crisis situations and, possibly, point to general ways of overcoming them.

Such further research would contribute to expanding existing best-practice advice (Seeger, 2006; Seeger \& Sellnow, 2019), which in its current form mainly relies on meta-examination of crises, toward practical advice based on a deeper understanding of the uniqueness of both specific risks and crises and of the organizations involved in responding to them. For the PHIs in our study, this could mean incorporating and emphasizing independence as a central virtue in their communication work prior to the next pandemic outbreak. Further, a general effort by PHIs, the ministry, and the government in constructing a joint ethos of the overarching health management field might be considered. Strengthening the public's understanding of the process of deciding on a response, including how scientific knowledge relies on hypotheses, attempts at falsification and scientific advancement, could serve as an inoculation against potential negative effects of disagreement between scientific authorities, while simultaneously strengthening the potential of virtue-based ethos strategies.

\section{ORCID}

Truls Strand Offerdal (i) https://orcid.org/oooo-0oo1-6631-1918 Sine Nørholm Just (1) https://orcid.org/0000-0002-4179-2708 Øyvind Ihlen 이 https://orcid.org/0000-0002-5001-3796

\section{References}

Aristotle. (trans. 2006). On rhetoric: A theory of civic discourse (2nd ed.). Oxford University Press.

Baumlin, J. S., \& Scisco, P. (2018). Ethos and its Constitutive Role in Organizational Rhetoric. In R. L. Heath \& Ø. Ihlen (Eds.), Handbook of Organizational Rhetoric and Communication: Foundations of Dialogue, Discourse, Narrative, and Engagement. (pp. 201-213). John Wiley and Sons.

Bitzer, L. F. (1968). The rhetorical situation. Philosophy \& rhetoric, 1(1), 1-14. https://www.jstor.org/stable/40236733 
Boyd, A. D., Furgal, C. M., Mayeda, A. M., Jardine, C. G., \& Driedger, S. M. (2019). Exploring the role of trust in health risk communication in Nunavik, Canada. Polar Record, 55(4), 235-240. https://doi.org/10.1017/s003224741900010x

Brekke, O. A., Ludvigsen, K., \& Bjørkdahl, K. (2017). Handling og usikkerhet. Norske myndigheters kommunikasjon om svineinfluensapandemien i 2009. Norsk statsvitenskapelig tidsskrift(o1), 54-77. https://doi.org/10.18261/issn.1504-29362017-01-05

Chess, C., \& Clarke, L. (2007). Facilitation of risk communication during the anthrax attacks of 2001: The organizational backstory. American Journal of Public Health, 97(9), 1578-1583. https://doi.org/10.2105/ajph.2006.099267

Chryssochoidis, G., Strada, A., \& Krystallis, A. (2009). Public trust in institutions and information sources regarding risk management and communication: Toward integrating extant knowledge. Journal of Risk Research, 12(2), 137-185. https:// doi.org/10.1080/13669870802637000

Covello, V. T. (2010). Strategies for overcoming challenges to effective risk communication. In R. L. Heath \& H. D. O 'Hair (Eds.), Handbook of risk and crisis communication (pp. 155-179): Routledge.

De Vocht, M., Claeys, A.-S., Cauberghe, V., Uyttendaele, M., \& Sas, B. (2016). Won't we scare them? The impact of communicating uncontrollable risks on the public's perception. Journal of Risk Research, 19(3), 316-330. https://doi.org/10.1080/13669877.2 014.971336

Eiser, J. R., Stafford, T., Henneberry, J., \& Catney, P. (2009). “Trust me, I'm a scientist (not a developer)": Perceived expertise and motives as predictors of trust in assessment of risk from contaminated land. Risk Analysis: An International Journal, 29(2), 288-297. https://doi.org/10.1111/j.1539-6924.2008.01131.x

Hardin, R. (1996). Trustworthiness. Ethics, 107(1), 26-42. https:// doi.org/10.1086/233695

Hardin, R. (2001). Conceptions and explanations of trust. In K. S. Cook (Ed.), Russell Sage foundation series on trust, Vol. 2. Trust in society (pp. 3-39). Russell Sage Foundation. 
Horsley, J. S. (2012). Planning for spontaneity: The challenges of disaster communication fieldwork. International Journal of Qualitative Methods, 11(3), 180-194. https://doi. org/10.1177/160940691201100301

Ihlen, Ø. (2009). Good environmental citizens? The green rhetoric of corporate social responsibility. In R. L. Heath, E. L. Toth, \& D. Waymer (Eds.), Rhetorical and critical approaches to public relations II (pp. 360-374). Routledge.

Ihlen, $\varnothing$. (2011). On barnyard scrambles: Toward a rhetoric of public relations. Management Communication Quarterly, 25(3), 455-473. https://doi.org/10.1177/0893318911409533

Ihlen, Ø., \& Heath, R. L. (2018). Introduction: Organizational Rhetoric. In Ø. Ihlen \& R. L. Heath (Eds.), The Handbook of Organizational Rhetoric and Communication (pp. 1-13). Wiley-Blackwell.

IPSOS. (2020). Presentasjon IPSOS omdømmeseminar 2020.

Jakobsen, S. E. (2020). Swedes trust their experts in the coronavirus crisis. Science Norway. https://web.archive.org/ web/20210123005621/https://sciencenorway.no/covid19crisis-epidemic/swedes-trust-their-experts-in-the-corona virus-crisis/1667514

Kjeldsen, J. (2015). Retorikk i vår tid: en innføring i moderne retorisk teori (8. oppl. ed.). Oslo: Scandinavian Academic Press.

Kvale, S., \& Brinkmann, S. (2009). Interviews: Learning the craft of qualitative research interviewing. Sage.

Lee, K. (2009). How the Hong Kong government lost the public trust in SARS: Insights for government communication in a health crisis. Public Relations Review, 35(1), 74-76. https://doi. org/10.1016/j.pubrev.2008.06.003

Liu, B. F., Bartz, L., \& Duke, N. (2016). Communicating crisis uncertainty: A review of the knowledge gaps. Public Relations Review, 42(3), 479-487. https://doi.org/10.1016/j. pubrev.2016.03.003

Liu, B. F., \& Horsley, J. S. (2007). The Government Communication Decision Wheel: Toward a Public Relations Model for the Public Sector. Journal of Public Relations Research, 19(4), 377393. https://doi.org/10.1080/10627260701402473 
Liu, B. F., \& Mehta, A. M. (2020). From the periphery and toward a centralized model for trust in government risk and disaster communication. Journal of Risk Research, 1-17. https://doi.org /10.1080/13669877.2020.1773516

McCroskey, J. C. (1966): Scales for the measurement of ethos. Communication Monographs, 33(1), 65-72. https://doi. org/10.1080/03637756609375482

McCroskey, J. C., \& Teven, J. J. (1999). Goodwill: A reexamination of the construct and its measurement. Communications Monographs, 66(1), 90-103. https://doi. org/10.1080/03637759909376464

Meredith, L. S., Eisenman, D. P., Rhodes, H., Ryan, G., \& Long, A. (2007). Trust influences response to public health messages during a bioterrorist event. Journal of Health Communication, 12(3), 217-232. https://doi.org/10.1080/10810730701265978

Nielsen, R. K. (2012). Ground wars: Personalized communication in political campaigns. Princeton University Press.

NIPH. (2016, 13.08.2019). Vision of the Norwegian Institute of Public Health. https://web.archive.org/web/20201027184001/ https://www.fhi.no/en/about/this-is-the-norwegian-instituteof-public-health/fhis-organisasjon-og-visjon/

Norwegian Department of Health. (2014). Nasjonal beredskapsplan pandemisk influensa. https://web.archive.org/web/ $20200305230256 /$ https://www.regjeringen.no/no/ dokumenter/nasjonal-beredskapsplan-pandemisk-influensa/ id2354614/

Norwegian Directorate of Health. (2019). About the Norwegian Directorate of Health. https://web.archive.org/ web/20200520005803/https://www.helsedirektoratet.no/ english/about-the-norwegian-directorate-of-health

Peters, R. G., Covello, V. T., \& McCallum, D. B. (1997). The determinants of trust and credibility in environmental risk communication: An empirical study. Risk Analysis, 17(1), 43-54. https://doi.org/10.1111/j.1539-6924.1997.tboo842.X

Schwartz-Shea, P., \& Yanow, D. (2009). Reading and writing as method: In search of trustworthy texts. In S. Ybema, D. Yanow, H. Wels, \& F. Kamsteeg (Eds.), Organizational ethnography: Studying the complexities of everyday life (pp. 56-82). Sage. 
Seeger, M. W. (2006). Best Practices in Crisis Communication: An Expert Panel Process. Journal of Applied Communication Research, 34(3), 232-244. https://doi.org/ 10.1080/00909880600769944

Seeger, M. W., \& Sellnow, T. L. (2019). Communication in Times of Trouble. John Wiley \& Sons.

Ursin, G., Skjesol, I., \& Tritter, J. (2020). The COVID-19 pandemic in Norway: The dominance of social implications in framing the policy response. Health Policy and Technology, 9(4), 663672. https://doi.org/10.1016/j.hlpt.2020.08.004

$\mathrm{Xu}$, Y., Margolin, D., \& Niederdeppe, J. (2020). Testing strategies to increase source credibility through strategic message design in the context of vaccination and vaccine hesitancy. Health Communication, 1-14. https://doi.org/10.1080/10410236.202 0.1751400

Ybema, S., Yanow, D., Wels, H., \& Kamsteeg, F. (2009). Studying everyday organizational life. In S. Ybema, D. Yanow, H. Wels, \& F. Kamsteeg (Eds.), Organizational ethnography: Studying the complexities of everyday life (pp. 1-20). Sage. 